\title{
Hans (Hansemann) Tønnesen, en diagnostisk gåte fra Amalie Skram
}

SAMMENDRAG I romanen S.G. Myre (1890), tredje bok i romanverket Hellemyrsfolket, lar Amalie Skram (1846-1905) oss møte Hans (Hansemann) Tønnesen, en 16 år gammel gutt med et «umåtelig stort hode», krampeanfall og et svært enkelt språk. Han blir plaget av ungene i gaten og er lavt verdsatt av sin mor, som omtaler ham som «udyr», «tussingen» og «treksel».

Antakelig har han hydrocephalus med makrokefali, epilepsi og psykisk utviklingshemning. Hansemanns spinkelhet, små tenner og sprukne hud tyder på veksthormonmangel som følge av hydrocephalus. Et par viktige detaljer, som at «han sprikte med fingrene og beveget dem i forskjellige retninger for å gjøre seg forståelig» og at «han ble rød av anstrengelse og skar fæle grimaser» når han prøvde å si noe, antyder en ekstrapyramidal, dyskinetisk cerebral parese. Han kan også være døv.

En av Amalie Skrams fettere hadde flere av disse trekkene og er en sannsynlig modell for Hansemann. Et spørsmål som melder seg for en nåtidig leser, er om Hansemann faktisk er så psykisk utviklingshemmet, eller om han er misforstått på grunn av sine fysiske handikap og kommunikasjonsvansker.

«La' nu det arme guttebarne' få vare i fre' der!» lød en skjennende fruentimmerstemme. "Dokker sku' skjemmest, Dokker, så Vorherre har gjort både friske og fardige, te fare sålissen avste' med en trave sà han, så hverken kan snakke eller slå ifra seg!» (...) Der ble et øyeblikks stillhet, og ungeflokken vendte seg og så på konen med flirende, måpende og til dels trossige ansikter.

"Jau, dokker har pyntet 'an pent te,» vedblev konen og pekte på en liten vissen gutte-

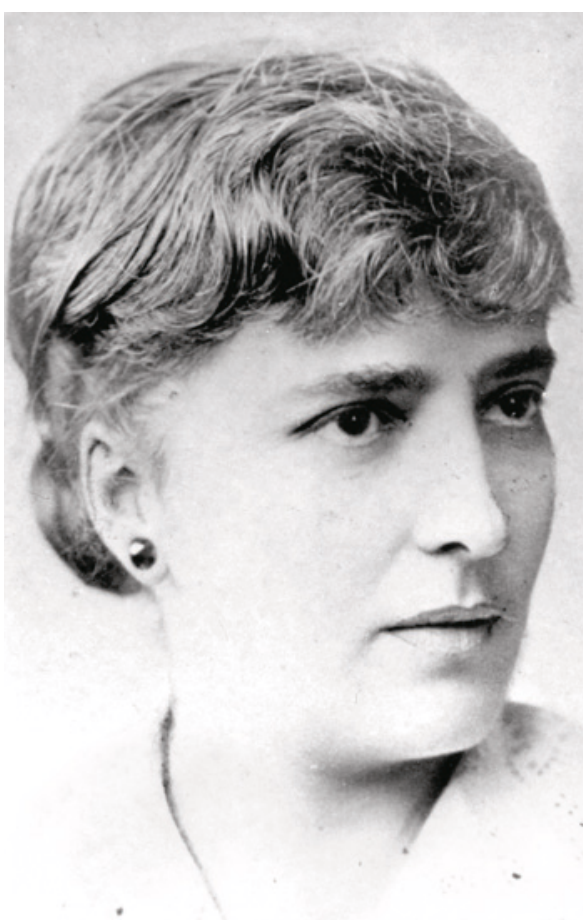

Amalie Skram, født Berthe Amalie Alver (1846-1905). Bildet er tatt ca. 1890. NTB scanpix skikkelse med et umåtelig stort hode, som kom til syne gjennem en åpning $i$ ringen. Klcerne hang i filler om ham og så ut, som om de hadde vart eltet $i$ søle, ansiktet var forgrått og fullt av gatesnaus; $i$ hånden holdt han et nytt blikkspann; håret strittet ut som på et villsvin, og føttene stakk til over anklene i rennestenens gråskitne vann (1, s. 244).

Slik møter vi Hans (Hansemann) Tønnesen i S.G. Myre (1890), tredje bok i Amalie Skrams firebindsverk Hellemyrsfolket (1887-98). Året er 1856, vi er i Bergen, og Hansemann er «over 16 år». Han tiltrekker seg oppmerksomhet på grunn av både utseende $\mathrm{og}$ atferd. Han blir tatt hånd om hjemme, men møter ikke mye forståelse; moren beskriver ham vekselvis som «udyr», «tussingen» og «treksel». Skram tegner gjennom et kort kapittel et så distinkt og detaljrikt bilde av gutten at det må være mulig nærme seg ham diagnostisk. Vi har allerede fått vite at han har et umåtelig stort hode og verken kan «snakke eller slå ifra seg». Etter at barnegjengen på ny har dukket Hansemann i rennesteinsvannet, fortsetter beskrivelsen:

Gutten $i$ rennestenen lå på rygg og holdt spannet $i$ begge hender høyt over hodet. Ansiktet var blåt og fordreiet, og kncerne oppkrympet til midt på brystet. Fråden sivet ut av munnvikene med det rennestensvann han hadde slukt, og han utstøtte et rallende, kraftesløst hyl, mens han bet i sin tykke underlebe med de bittesmå brune tenner $(1$, s. 245).

Senere velter han seg i krampetrekninger både en og to ganger. Deretter faller Hansemann i søvn.

\author{
Bjørnar Hassel \\ bjornar.hassel@ffi.no \\ Avdeling for nevrohabilitering \\ Oslo universitetssykehus, Ullevål \\ Forsvarets forskningsinstitutt
}




\section{Bare en tussete unge?}

Det later til at vi har å gjøre med en gutt med makrokefali, det følger av hans umåtelig store hode. Hansemanns kramper blir i boken omtalt som «begavinger», en betegnelse på epileptiske anfall (2), og den ledsagende cyanosen, leppebittet og munnfråden taler også for epilepsi. At det skal være noe mentalt i veien med gutten, blir tydelig målbåret av en nabokjerring som omtaler ham som en «tussete unge», og det blir påstått at han ikke kan snakke. Altså må vi tro han er psykisk utviklingshemmet.

Hansemann har likevel litt språk, viser det seg. Til moren sier han «Mi ha, mi ha» når det er noe han vil ha. Men det er noe eget med talen hans: «Spe, spe, spe,» klynker han når han vil si «spannet», mens han blir rød av anstrengelse og skjærer «fæle grimaser». Samtidig spriker han med fingrene og beveger dem i forskjellige retninger. Disse fingerbevegelsene må vi også stusse ved: de virker atetotiske. Sammen med grimaseringen, som ledsager taleforsøkene, tyder de på cerebral parese. En opplysning vi mangler, er hvordan ganglaget hans er. Vi hører ingenting om saksegange eller tågang slik spastisk cerebral parese kan gi. Heller ikke sies det noe om halvsidige, hemiplegiske, symptomer. Men Hansemann går rundt $\mathrm{i}$ byen på egen hånd, så slike plager kan ikke være dominerende. Hans cerebrale parese må være vesentlig ekstrapyramidal og dyskinetisk, med de atetotiske fingerbevegelsene og grimaseringen. Til grunn for alle disse plagene ligger antakelig en tidlig ervervet hydrocephalus, som er assosiert både med epilepsi, psykisk utviklingshemning og cerebral parese (3-5)

Hansemann er liten for alderen og «veier ikke mange markene, stakkaren, skjønt (...) han ska' være over 16 år», som konen i gaten sier (1, s. 246). Han har en «kyllingspinkel hals», «rørtynne arme» og «sprukne små hender». Veksthemning passer godt med hydrocephalus, som kan medføre redusert frigjøring av veksthormon (6). Av samme grunn får man tynn og sprukken hud (7) og forsinket frembrudd av permanente tenner (8). Det siste forklarer, kanskje sammen med karies, Hansemanns «bittesmå brune tenner». Spinkelheten skyldes ikke fattigdom og underernæring. Faren, Pitter Tønnesen, arbeider som gesell på Bryggen og har dermed en overordnet stilling ved et av handelshusene der (9). Tønnesens hjem har et velfylt kjøkken og «to stovver på stas, med damask på stolene og messing-spyttebakker». Og ifølge moren eter og drikker Hansemann som en blind merr. Det må bety at han spiser godt. Men andre faktorer kan kanskje også spille inn. Med alt det rennesteinsvannet han får i seg, ville det ikke være rart om gutten hadde innvollsorm.

Hansemann klasker den høyre neven i den venstre for å illustrere hvordan han har hamret spannet til, og han peker vekselvis på moren og på seg selv for å vise at hun skal få det av ham. Har han utviklet sitt eget tegnspråk? Og når moren sier at hun forstår, smiler han og nikker så vi tror han har hørt henne, men de to har åpenbart ansiktet vendt mot hverandre, så han kan ha lest på leppene. Hansemann kan altså være døv. At hydrocephalus er assosiert med døvhet, f.eks. via meningitt eller encefalitt tidlig i livet, var medisinsk viten på Amalie Skrams tid (3).

Moren klager: «Og så svinaktig så han er! Slike sengklær, både på den ene måten og på den andre måten, med uterlighet osså ...» Om dette er inkontinens i egentlig forstand eller om det er knyttet til nattlige epilepsianfall, vet vi ikke. Hva som ligger i «uterlighet» her, er uklart. Det er noe uhumskt i tillegg til urin og avføring. Ordbog over det danske sprog (9) angir bl.a. disse betydningene av uterlighed: «usømmelig, skammelig handling (...) ofte om groft usædelig optræden.» Det er mulig at moren refererer til onani. Vi kan imidlertid ut fra beskrivelsen av sengetøyet anta at Hansemann begrenser seg til «det kott ved siden av kjøkkenet hvor han hadde sitt sovested» og altså her legger for dagen en viss bluferdighet og forståelse av sosiale normer.

Vi kan oppsummere de kliniske iakttakelsene med at Hansemann antakelig har hydrocephalus med makrokefali, epilepsi, cerebral parese og en viss grad av psykisk utviklingshemning, og kanskje er han døv.

\section{En litterær konstruksjon eller et faktisk menneske?}

Hansemann har en litterær funksjon i boken. Han gir dybde til skildringen av Bergens-miljøet, og med sitt store hode og andre pussigheter inngår han i det glyptoteket av vanskjebner som boken beskriver. Han illustrerer dels den håpløsheten som er knyttet til slekten hans, Hellemyrsfolket, dels et menneskes sårbarhet i en ubarm- hjertig verden. Følgelig kan man spørre om han bare er en litterær konstruksjon, noe som kanskje ville tatt brodden av våre diagnostiske fremstøt. Amalie Skram regnes som vår fremste forfatter innen naturalismen, en litterær retning preget av realistisk gjengivelse av samfunnsforhold og et pessimistisk sosialt grunnsyn. Skal vi tro at Hansemann er en realistisk gjengivelse av et menneske Skram har sett, eller skal han først og fremst fylle en «pessimistisk funksjon»? Skram brukte modeller for romanpersonene sine. Hansemanns mormor Oline er en forfyllet liten bondekone som raver rundt i smauene og blir kalt Småfylla. Både hun og hennes svirebror, Tippe Tue, var virkelige personer som er beskrevet $i$ en samtidig selvbiografi (10).

Det er ingen publiserte kilder å trekke på når det gjelder Hansemann selv. Skrams brev fra denne perioden er gitt ut (11), og de gir ingen opplysninger om ham. Forfatteren Gunnar Staalesen, som bl.a. har dramatisert Hellemyrsfolket for Den Nationale Scene i Bergen, har imidlertid viktige opplysninger. Amalie Skram diktet mye av sin egen families historie inn i Hellemyrsfolket. En fetter av henne, Hans Petter Hansen

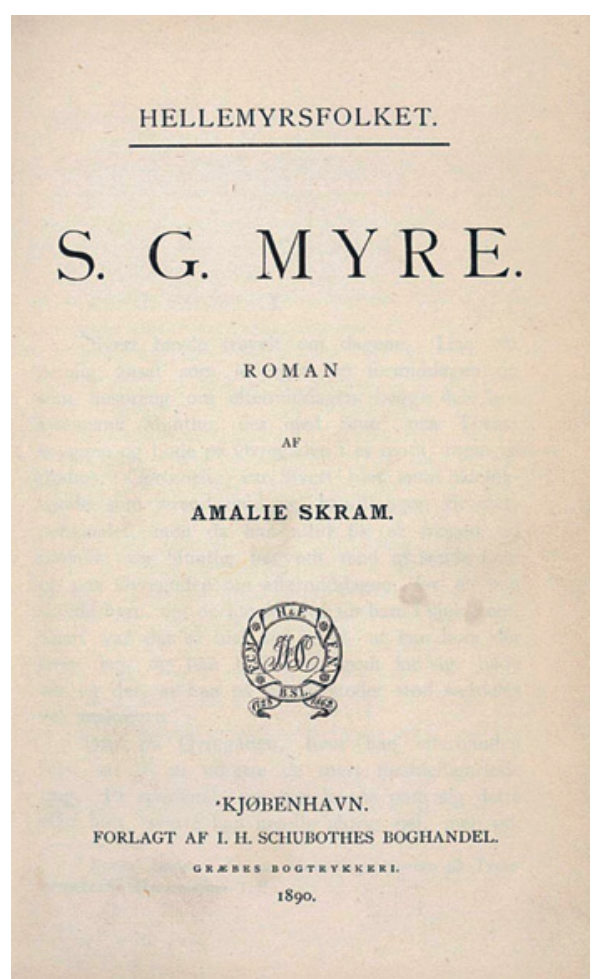

S.G. Myre (1890), tredje bok i Amalie Skrams firebindsverk Hellemyrsfolket (1887-98) 


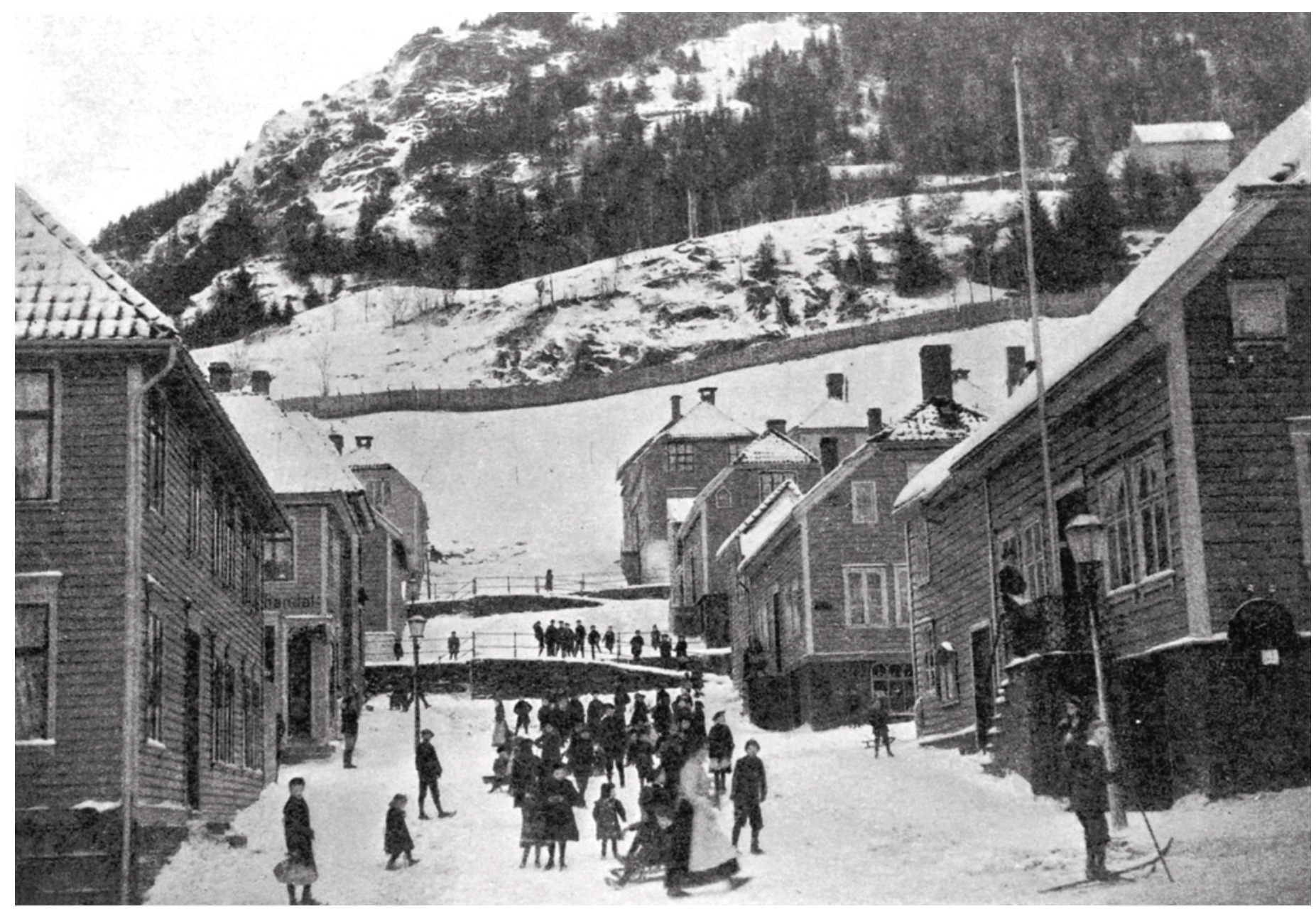

Arbeiderkvarteret Krohnengen i 1870-årene. Fra Christian Koren Wibergs Bergensk kulturhistorie

(1851-1912) (12), vokste opp i det strøket av Bergen der Hansemann bor, Steinkjelleren. Hans far var, som Hansemanns, gesell. Hans Petter hadde ifølge folketellingen fra 1865 «Legems svaghed» (13). I folketellingen fra 1875, da han var 24 år, står det «Lam 6 år gammel» (Gunnar Staalesen, personlig meddelelse).Av konfirmasjonsboken for Korskirken fra 1867 fremgår det at Hans Petter ble konfirmert først to år etter sine jevnaldrende. Mens alle de andre konfirmantene får en spesifikk vurdering av kunnskaper, flid og evner, står det om Hans Petter bare «Temmelig brav» (14), altså «temmelig bra» (9).

Under folketellingene i 1900 og 1910 er han forsørget av Bergens fattigvesen i 1900 er navnet hans markert med en «D» for «døv» (15) og i 1910 med en «a» for «aandssvag» (16). Han bor da hos sin tante og onkel på gården Nedre Tveiten i Alversund utenfor Bergen. De kaller ham «Hansemann». Om denne Hans Petter svarer til romanens Hansemann i ett og alt, kan vi ikke vite, men mye taler for at Skram gjengir en person hun har sett på nært hold. Den innbyrdes konsistensen mellom Hansemanns lyter tyder også på at hun gjengir er en virkelig person, slik at det gir mening å fortsette utredningen.

\section{Mulige årsaker}

Hansemanns umåtelig store hode skyldes temmelig sikkert hydrocephalus. Økt intrakranialt trykk før skallebeinssømmene lukker seg gir makrokefali. Intrakraniale infeksjoner pre- eller postnatalt kan gi hydrocephalus (17), og bl.a. røde hunder, meslinger og syfilis, som alle kan forårsake tilstanden, var vanlige i 1850-årenes Bergen (18). Intraventrikulær blødning, eventuelt som følge av intrakranial infeksjon, var også en vanlig årsak til hydrocephalus (19). Chiaris og Dandy-Walkers malformasjoner forekom da som nå, men er kanskje mindre sannsynlige når det gjelder Hansemann, som ikke frembyr tydelige cerebellære eller andre typiske symptomer. Dødeligheten ved hydrocephalus før moderne shuntbehandling var høy, rundt $80 \%$ i én studie (4), men hos dem som overlevde, kunne tilstanden stabilisere seg.

Hydrocephalus kan gi forskjellige skader på hjernen. Ekstrapyramidal cerebral parese med dyskinesi, som hos Hansemann, tyder på bilateral basalganglieskade (20). Det er mulig at intrakranial trykkstigning fortrinnsvis gir en skade av basalgangliene som ligger an mot ventrikkelveggene. På den annen side kan en intraventrikulær blødning ledsages av en global cerebral hypoksi, som primært kan skade basalgangliene (21) i tillegg til å gi nedsatt resorpsjon av cerebrospinalvæske.

Selv om Hansemanns store hode sannsynligvis skyldes en ervervet tilstand som infeksjon eller blødning, er en genetisk betinget tilstand også en mulighet. Et søk i OMIM-databasen gir 262 forskjellige genetiske tilstander som ledsages av makrokefali (22). Mange av disse er knyttet til en abnormt stor hjerne, megaloenkefali. To tilstander er samtidig assosiert med epilepsi, psykisk utviklingshemning og dystoni, nemlig enzymdefektsykdommene L-2hydroksyglutarsyreuri og (mitokondriell) kompleks 1-mangel. Begge kan debutere svært tidlig og siden være nokså stabile (23, 24), slik tilfellet later til å være for Hansemann. I tillegg til de cerebrale symptomene innebærer disse enzymdefektene veksthemning, noe Hansemann jo har. Glutarsyreuri type 1 er en annen tilstand som kan gi makrokefali, psykisk utviklingshemning, dystoni og epilepsi (25). En genetisk betinget tilstand hos Hansemann kan mistenkes, fordi hans to søsken døde som små. Men moren omtaler disse to som «vakre, friske, velskapte», i klar motsetning til Hansemann, som hun kaller et utyske, så en viss forskjell har det vært på barna. 


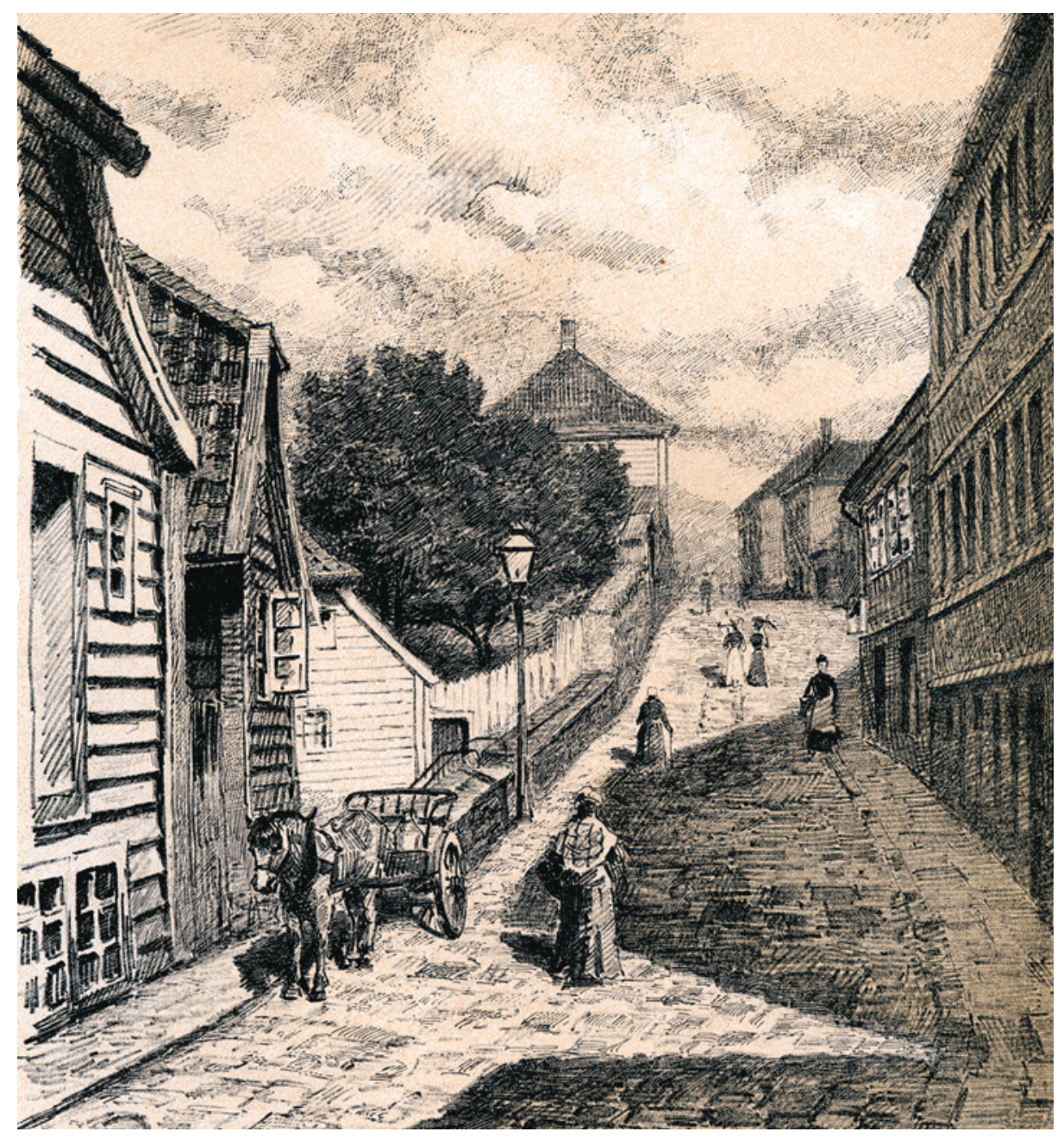

Steinkjellergaten, tegnet av August Johannessen i 1888. Steinkjellergaten 13, der Amalie Skrams fetter Hans Petter ble født, er andre hus på høyre hånd. Dette huset, med en fuktig fjellvegg bak, er sannsynligvis det huset Skram beskriver som Hansemanns hjem. I 1890-årene ble det erstattet med et mer moderne fleretasjes murhus. Publiseringstillatelse er forsøkt innhentet

\section{Behandlingen i våre dager}

Hellemyrsfolket skildrer et Bergen uten større helse- og sosialvesen til å ta seg av all den fattigdom og fyll, sykdom og omsorgssvikt vi hører om. Bergen Døvstuminstitut åpnet i 1850, men dersom Hansemann var regnet som åndssvak, fikk han neppe adgang der selv om han skulle være døv. Han ville kanskje hatt nytte av Abnormskoleloven (1881) som ga skoleplikt for blinde, døve og åndssvake, men i 1856 var det langt frem dit.

Hydrocephalus med makrokefali er en sjeldenhet i Norge i dag, men vanligere i deler av verden der behandling mangler. Pasienter med cerebral parese, epilepsi og psykisk utviklingshemning trenger tverrfaglig spesialistbehandling, gjerne i regi av en nevrohabiliteringsavdeling ved ett av sykehusene våre. Dersom han ikke kunne klare seg på egen hånd eller familien ikke kunne ta hånd om ham hjemme, ville Hansemann i dag fått tilbud om å bo kollektivt sammen med andre med liknende utfordringer i en døgnbemannet omsorgsbolig. Han ville blitt fulgt opp regelmessig angående syn, hørsel og tannhelse. Han ville fått
Litteratur

Skram A. S.G. Myre, 3. roman i Hellemyrsfolket. Kap. V. Bergen: Vigmostad og Bjørke, 2002 241-52.

2. Norsk historisk leksikon. 2. utg. Oslo: Cappelen, 2004. www.lokalhistoriewiki.no/index.php/ Leksikon: Begaving (25.6.2012).

3. Ireland WW. The mental affection of children, idiocy, imbecility and insanity. London: Churchill, 1898: $133-42$.

4. Laurence KM, Coates S. The natural history of hydrocephalus. Detailed analysis of 182 unoperated cases. Arch Dis Child 1962; 37: 345-62.

5. Pharoah PO, Cooke T, Johnson MA et al. Epidemiology of cerebral palsy in England and Scotland 1984-9. Arch Dis Child Fetal Neonatal Ed 1998; 79 F21-5.

6. Hochhaus F. Butenandt O, Schwarz H-P et al. Auxological and endocrinological evaluation of children with hydrocephalus and/or meningomyelocele. Eur J Pediatr 1997; 156: 597-601.

7. Black MM, Shuster S, Bottoms E. Skin collagen and thickness in acromegaly and hypopituitarism. Clin Endocrinol (Oxf) 1972: 1: 259-63.

8. Kosowicz J, Rzymski K. Abnormalities of tooth development in pituitary dwarfism. Oral Surg Oral Med Oral Pathol 1977; 44: 853-63.

9. Ordbog over det danske sprog. http://ordnet.dk/ ods/ordbog (28.9.2012).

10. Janson K. Hvad jeg har oplevet: livserindringer. 2. opplag. Kristiania: Gyldendalske Boghandel Nordisk Forlag, 1913: 6.

11. Garton J. red. Elskede Amalie. Brevene mellom Amalie og Erik Skram. Tre bind. Oslo: Gyldendal, 2002

12. Hordaland fylke, Alversund i Alversund, Ministerialbok nr. A 3 (1897-1926), Døde og begravede 1910-1912, side 152. www.arkivverket.no/ URN:NBN:no-a1450-kb20050725020129.jpg (21.9.2012)

13. Folketelling 1865 for 1301 Bergen kjøpstad. http://digitalarkivet.arkivverket.no/ft/person/ pf01038249027287 (21.9.2012)

14. Bergen fylke, Korskirken, Ministerialbok nr. C 3 (1854-1868), Konfirmerte menn 1867, side 119 www.arkivverket.no/URN:NBN:no-a1450kb20050819020416.jpg (21.9.2012)

15. Digitalarkivet. 1900-telling for 1257 Alværsunds. http://digitalarkivet.no/cgi-win/WebCens.exe? slag=visbase \&siden $r=6 \&$ filnamn $=f 01257 \&$ gardpostn $r=292 \&$ personpostn $r=1913 \&$ merk $=$ 1913\#ovre (21.9.2012)

16. Digitalarkivet. Folketelling 1910 for 1257 Alversund herred. http://digitalarkivet.arkivverket.no/ft/ person/pf01036700002327 (21.9.2012).

17. Joó JG, Tóth Z, Beke A et al. Etiology, prenatal diagnostics and outcome of ventriculomegaly in 230 cases. Fetal Diagn Ther 2008; 24: 254-63.

18. Medicinalberetning for Bergen. 1851 ved Stadsfysikus O.B. Heiberg. Riksarkivet, Oslo.

19. Hess JH. Premature and congenitally diseased infants. New York: Lea and Febiger, 1922 www. neonatology.org/classics/hess1922/ hess.13.html (25.6.2012).

20. Hoon AH Jr, Reinhardt EM, Kelley RI et al. Brain magnetic resonance imaging in suspected extrapyramidal cerebral palsy: observations in distinguishing genetic-metabolic from acquired causes. J Pediatr 1997: 131: 240-5.

21. Takeoka M, Soman TB, Yoshii A et al. Diffusionweighted images in neonatal cerebral hypoxicischemic injury. Pediatr Neurol 2002; 26: 274-81.

22. OMIM (Online Mendelian inheritance in Man), 2012 Søkeord: macrocephaly. www.ncbi.nlm.nih.gov/ omim (25.6.2012).

23. Kranendijk M, Struys EA, Salomons GS et al. Progress in understanding 2-hydroxyglutaric acidurias. J Inherit Metab Dis 2012: 35: 571-87.

24. Loeffen JL, Smeitink JA, Trijbels JM et al. Isolated complex I deficiency in children: clinical, biochemical and genetic aspects. Hum Mutat 2000; 15 $123-34$.

25. Kyllerman M, Skjeldal OH, Lundberg M et al. Dystonia and dyskinesia in glutaric aciduria type I: clinical heterogeneity and therapeutic considerations. Mov Disord 1994; 9: 22-30

fra Nevrologisk avdeling, Rikshospitalet, og Avdeling for nevrohabilitering, Ullevål sykehus. Forfatter har fylt ut ICMJE-skjemaet og oppgir ingen interessekonflikter.
Mottatt 10.8. 2012, første revisjon innsendt 22.9. 2012, godkjent 27.9. 2012. Medisinsk redaktør Erlend Hem. 